\title{
The accuracy of ultrasound-guided lung biopsy pathology and microbial cultures for peripheral lung lesions
}

\author{
Zhen-Long Zhao, Li-Li Peng, Ying Wei, Yan Li, Ge-Meng Wang, Ming-An Yu \\ Department of Interventional Ultrasound Center, China-Japan Friendship Hospital, Beijing 100029, China \\ Contributions: (I) Conception and design: ZL Zhao, MA Yu; (II) Administrative support: MA Yu; (III) Provision of study materials or patients: Y Wei, \\ LL Peng; (IV) Collection and assembly of data: Y Li, LL Peng; (V) Data analysis and interpretation: GM Wang, ZL Zhao; (VI) Manuscript writing: \\ All authors; (VII) Final approval of manuscript: All authors. \\ Correspondence to: Ming-An Yu. Department of Interventional Ultrasound Center, China-Japan Friendship Hospital, Beijing 100029, China. \\ Email: yma301@163.com.
}

\begin{abstract}
Background: Ultrasound-guided lung biopsy (USLB) is a minimally invasive, real-time, safe and effective way to diagnose peripheral lung lesions. USLB is now widely used in clinical practice. However, the accuracy of USLB lacks large sample studies, and specimens from USLB are seldom used for microbial cultures. In this study, the efficiency of diagnosing tumours and infectious diseases with USLB is investigated, and the safety of USLB is evaluated.

Methods: From September 2015 to August 2018, a total of 507 cases of USLB were retrospectively reviewed, including the pathological results, microbial culture results and complications. The final diagnosis was confirmed by clinical diagnosis and follow-up. The technical success rate and accuracy of USLB were calculated.

Results: Six patients were excluded because they were lost to follow-up. A total of 501 patients were finally included (335 males and 166 females). The diagnostic accuracy of USLB was $82.0 \%$. The accuracy of USLB in diagnosing lung tumours was $88.5 \%$ and that for diagnosing special infections was $55.2 \%$. The positive rate of USLB lung tissue cultures was $18.3 \%$. USLB can diagnose some microbial infections with high accuracy, such as mycobacterial infections, and Cryptococcus neoformans, Aspergillus fumigatus and Burkbolderia cepacia infections.

Conclusions: USLB is a safe and effective method for diagnosing peripheral lung lesions with high accuracy and a low complication rate. Lung tissue pathology and cultures have good diagnostic value for tuberculosis and fungi infections. Lung tissue cultures can also diagnose bacterial infections and can contribute to the selection of antibiotics.
\end{abstract}

Keywords: Ultrasound; lung; biopsy; microbial culture; pulmonary infections

Submitted Apr 19, 2019. Accepted for publication Dec 10, 2019.

doi: $10.21037 /$ jtd.2019.12.92

View this article at: http://dx.doi.org/10.21037/jtd.2019.12.92

\section{Introduction}

Lung nodules and lung consolidation are common manifestations of respiratory diseases, and many lung lesions require pathological examinations and cultures to clarify the cause and pathogen. It is important to know whether the lesion is malignant and the pathogen of the infectious disease before a clinical treatment is decided upon.
Imaging-guided percutaneous lung biopsy, endobronchial ultrasound (EBUS)-guided lung biopsy, bronchoscopy transbronchial lung biopsy (TBLB) and thoracoscopy lung biopsy are important methods in the diagnosis of lung lesions. In comparison to other methods, imaging-guided percutaneous lung biopsy is minimally invasive, safe and can obtain tissue from inside the lesion directly. With the 
development of imaging technology, the space resolution of computed tomography (CT) and ultrasound (US) have improved greatly, and these two methods are widely applied in clinical practice to guide lung biopsy.

CT has high image resolution and can guide the biopsy of any part of the lung in theory. Some studies show that CT-guided lung biopsy has a higher yield than EBUSguided lung biopsy in the diagnosis of peripheral pulmonary lesions $(1,2)$. However, CT-guided lung biopsy has fatal complications, such as systemic air embolism, which may not be noticed in time (3-9). Additionally, pulmonary haemorrhage and pneumothorax frequently occur during CT-guided lung biopsy $(4,10)$, especially in the biopsy of part-solid lesions (10). One study showed that percutaneous lung biopsy-related pneumothorax occurred in $27.3 \%$ CT-guided lung biopsies, of which $25.1 \%$ of the patients developed pneumothorax during the follow-up visits (11), and a routine chest $\mathrm{X}$-ray was suggested after a CT-guided lung biopsy (12). Delayed pneumothorax also occurs during bronchoscopy transbronchial lung biopsy (13).

A recent study showed that ultrasound-guided lung biopsy (USLB) of peripheral lung lesions is safer and faster than CT-guided lung biopsy $(14,15)$, and its diagnostic yield to establish a malignant diagnosis is acceptable (15). However, the accuracy of USLB lacks large sample studies. USLB has many advantages. Ultrasound has real-time guidance and can reach the lesion quickly and precisely. The vessels in the target lesion and adjacent lung tissue can be observed clearly by colour Doppler flow imaging (CDFI), and most biopsy-related lung haemorrhages can be avoided. If lung haemorrhage or pneumothorax occurs, they can be observed with ultrasound in time, and emergency treatment can be provided. In addition, the lung tissue obtained by biopsy can not only be used to distinguish malignant lesions from benign lesions but can also be used to detect specific pathogens for drug testing and antibiotic selection. However, lung tissue culture is not common in clinical practice and lacks relevant studies.

In this study, the efficiency of diagnosing tumours and infectious diseases with USLB is investigated, and the safety of USLB is evaluated.

\section{Methods}

\section{Patients}

In the study, target peripheral lung lesions were defined as lesions adjacent or less than $3 \mathrm{~cm}$ away from the pleura, which could be visualised by ultrasound. The original ultrasound images, laboratory examination results, pathological results, culture results (biopsy, bronchoalveolar lavage fluid and sputum) from 507 percutaneous ultrasound-guided pleural biopsies from 489 patients between September 2015 and August 2018 were retrospectively reviewed. The patients were all from China-Japan Friendship Hospital with undiagnosed and untreated lung lesions. The exclusion criteria were as follows: (I) coagulation function was severely abnormal (platelet count $<60 \times 10^{9} / \mathrm{L}$, prothrombin time $>20 \mathrm{~s}$ or prothrombin time activity $<60 \%$ ) without the need for emergency treatment; (II) mental diseases that would cause the patient to not cooperate; and (III) the final diagnosis of the lung lesions was uncertain and was followed up for less than 6 months or was lost to follow-up.

\section{Procedure}

The patients were placed in a lateral decubitus, dorsal decubitus or sitting position according to the puncture point. Before the biopsy, an ultrasound scanner (Toshiba Aplio500, Japan) was used to observe the position, size and shape of the lesion to work out a puncture plan. An 18G (Argon Medical Devices, Inc.) automated cutting needle was used to perform the biopsy with the patient under local anaesthesia with $2 \%$ lidocaine. Three punctures were performed. Two specimens were fixed in $10 \%$ formalin for histopathological examinations, and one specimen was placed into normal saline for culture. CDFI was used to evaluate the presence of lung haemorrhage, and reptilase (Hemocoagulase Atrox for Injection, Nuokang Medicine) was injected intramuscularly when necessary. The method of detecting microbes included acid-fast staining, Gomori methenamine silver staining, normal bacterium culture, normal fungal culture, mycobacterium culture and the GeneXpert system.

\section{Result classification}

The pathological and culture results of USLB were classified into 7 groups. The no lung tissue group refers to patients without lung tissue in the biopsy samples. The nonspecific inflammation group refers to the cases of chronic or acute inflammation. The special infection group refers to cases of positive pathogen findings. The tumour group refers to cases of tumours. The immune disease group refers 
Table 1 The pathological and culture results of USLBs

\begin{tabular}{llc}
\hline Type of result & Group of result & USLB case count \\
\hline No lung tissue & No lung tissue & 20 \\
Inflammation & $\begin{array}{l}\text { Non-specific } \\
\text { inflammation } \\
\text { Special infection }\end{array}$ & 239 \\
& Immune disease & 68 \\
Tumour & Tumour & 6 \\
Tumour with special & Compound disease & 7 \\
infection & & 3 \\
Others & Others & \\
\hline
\end{tabular}

USLB, ultrasound-guided lung biopsy.

to cases of immune disorders. The compound disease group refers to cases of both tumours and special infections. The other group refers to cases of other types of pathological results.

The gold standard was the final clinical diagnosis. If the pathological and culture results of the USLB were in accordance with the clinical diagnosis, whether the pathological result directly gave the clinical diagnosis or the pathological result was the typical manifestation of the clinical diagnosis, the USLB was considered to have made a correct diagnosis. If final clinical diagnosis was indefinite before discharge, in other words, the biopsy pathology and other clinical examinations had negative findings, the patients were advised to undergo regular follow-up, and the follow-up results were used as the gold standard. The follow-up results were stratified into two types. The negative follow-ups refer to cases where the lung lesion remained stable, decreased or disappeared on the CT scans in 6 months, or the lesion was still negative based on a second biopsy performed 6 months later. The positive follow-ups are cases in which the lung lesion had positive findings in a second biopsy pathology or clinical examination 6 months after USLB.

\section{Results}

A total of 501 cases of USLB were reviewed (6 patients were excluded because they were lost to follow-up), and 18 patients underwent two procedures. The study included 335 males and 166 females. The age of the patients ranged from 15 to $91(60 \pm 15)$ years. All patients had specimens for pathological examination, and 317 patients had specimens for lung tissue culture. The length of the lesion on the CT images ranged from 1.3 to $11.9 \mathrm{~cm}(5.01 \pm 2.57 \mathrm{~cm})$. The lesions consisted of 40 cases of ground glass opacity and 461 cases of solid or part-solid lesions. The distance from the lesion to the parietal pleura (including the pleural effusion) ranged from 0 to $5.2 \mathrm{~cm}(2.12 \pm 1.77 \mathrm{~cm})$.

The pathological and culture results of USLB are shown in Table 1.

Lung tissue was successfully obtained in 481 of the 501 lesions for pathological examination with USLB, so the technical success rate of USLB was $96.0 \%$. The 20 cases in which USLB did not obtain lung tissue included those of lung abscess, pneumonia, lung cancer and idiopathic interstitial pneumonia. The accuracy of classifying the type of lesion (benign or malignant lesion) was $93.4 \%$ (468/501). The diagnostic accuracy (the pathological results and culture results were in accordance with the gold standard) of USLB was $82.0 \%$ (411/501). USLB missed 20 tumours, so the accuracy of diagnosing tumours was $88.5 \%$ (154/174). The positive rate of USLB lung tissue cultures was $18.3 \%$ (58/317). Fifty-five percent (58/105) of the cases of special infection were diagnosed by USLB (including through staining, GeneXpert and culture). The accuracy of diagnosing mycobacteria infection was $62.7 \%$ (27/43). The details of the final diagnoses are shown in Tables 2,3.

Generally, the gas part of the lesion is avoided during the biopsy in case of pneumothorax (Figure 1). A total of 45 patients had complications related to USLB, and one patient had a fatal lung haemorrhage but survived with emergency treatment. The details are shown in Table 4.

\section{Discussion}

USLB has many advantages over thoracoscopy and CTguided lung biopsy. USLB is minimally invasive, does not need radiation, and provides real-time guidance, which can enable the operator to adjust the biopsy angle precisely and notice complications in time. During USLB, the operator can avoid large bronchi and vessels, which may reduce the probability of haemorrhage and pneumothorax. USLB is performed under local anaesthesia and is safer and simpler than thoracoscopy. The technical success rate of USLB was $96.0 \%$, which means that in most cases, lung tissue can be successfully obtained. The 20 cases in which USLB could not obtain lung tissue were those of lung abscess, pneumonia, lung cancer and idiopathic interstitial pneumonia. In the cases of lung abscess, lung cancer or severe pneumonia, there could be a large range of 
Table 2 The details of the cases in which USLB was in accordance with the gold standard

\begin{tabular}{|c|c|}
\hline Group of result & Gold standard (number of cases) \\
\hline Special infection (58 cases) & $\begin{array}{l}\text { Special pathogenic bacteria [18]: Nocardia asteroids [1], Klebsiella pneumoniae [1], Staphylococcus } \\
\text { aureus [2], Staphylococcus cohnii [1], Staphylococcus hominis [2], Burkholderia cepacia [5], } \\
\text { Pseudomonas aeruginosa [1], Enterococcus gallinarum [1], Streptococcus constellatus [1], } \\
\text { Streptococcus intermadius [1], Acinetobacter baumanii [2] }\end{array}$ \\
\hline Tumour (154 cases) & $\begin{array}{l}\text { Pulmonary adenocarcinoma [66], lung squamous carcinoma [42], small cell lung cancer [10], non-small } \\
\text { cell lung cancer not otherwise specified [3], metastatic tumour [13], neuroendocrine carcinoma [4], } \\
\text { adenosquamous carcinoma of the lung [2], pulmonary lymphoma [7], epithelioid angiosarcoma of lung [1], } \\
\text { lung sarcomatoid carcinoma [6] }\end{array}$ \\
\hline Immune disease (5 cases) & Lipoid pneumonia [2], IgG4-related disease [2], pulmonary alveolar proteinosis [1] \\
\hline Compound disease (7 cases) & Lung cancer with special infection [6], metastatic tumour with special infection [1] \\
\hline Other ( 3 cases) & Pulmonary infarction [3] \\
\hline
\end{tabular}

USLB, ultrasound-guided lung biopsy.

Table 3 The details of the cases in which the USLB failed to give the correct diagnosis

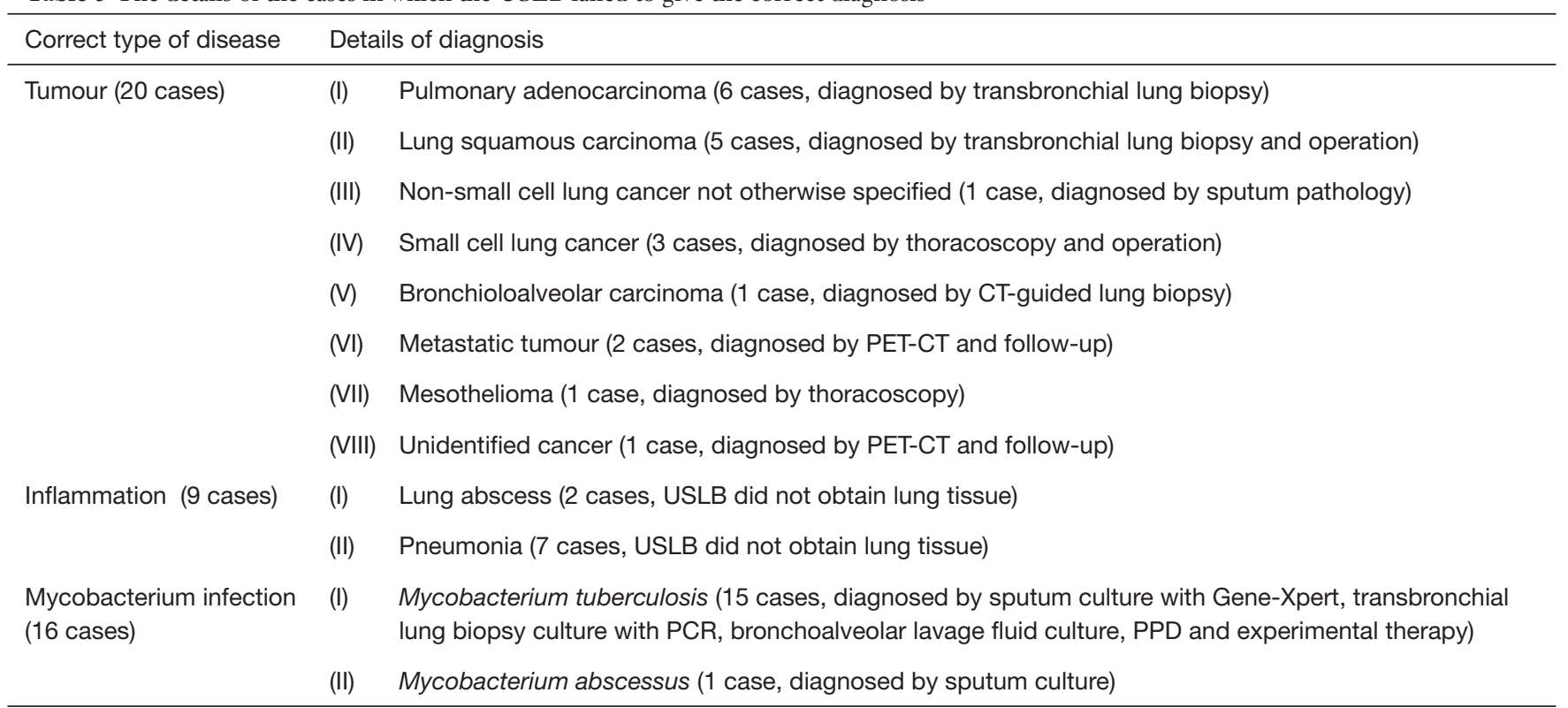

Table 3 (continued) 
Table 3 (continued)

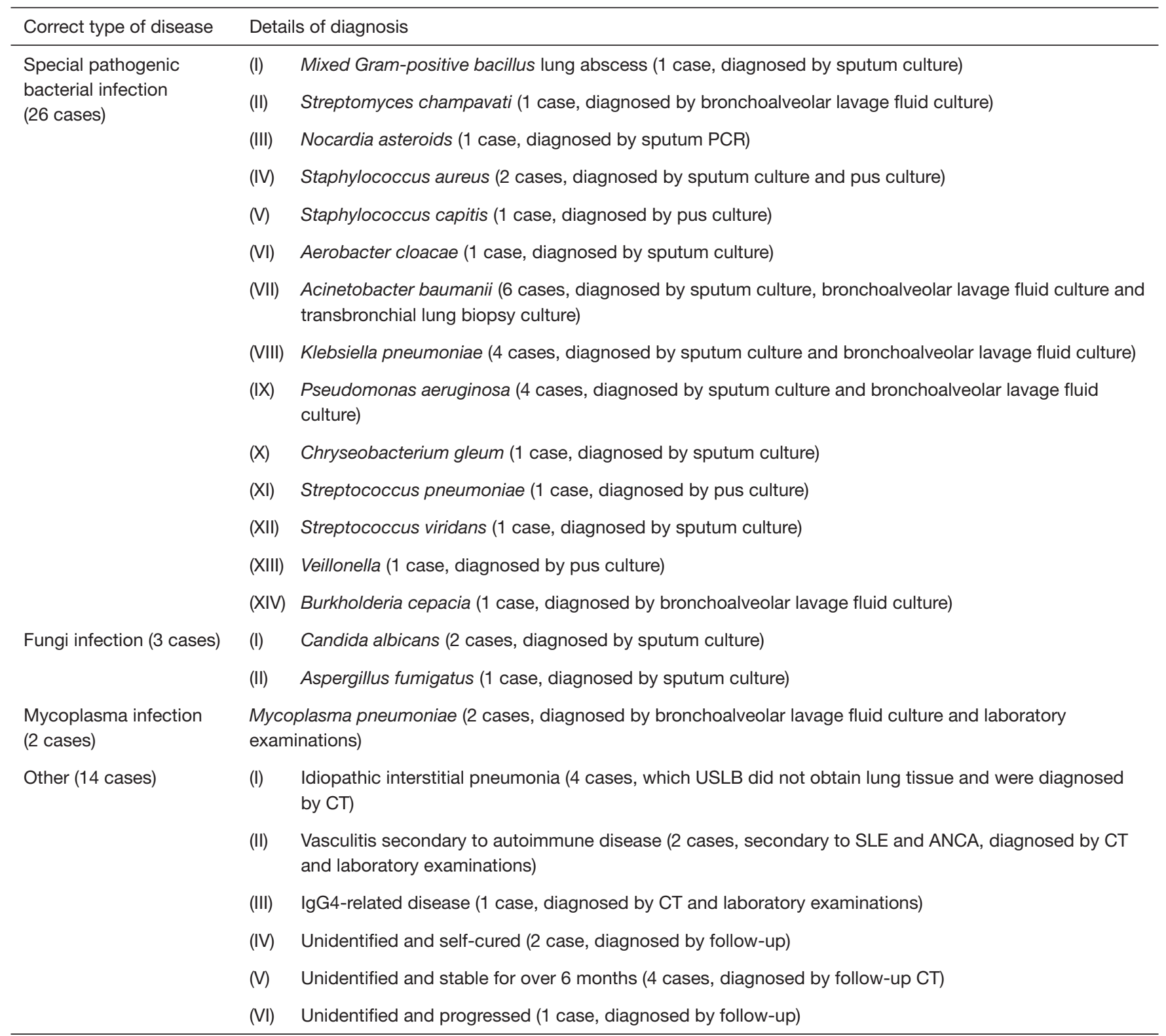

USLB, ultrasound-guided lung biopsy.

necrosis, and USLB may fail to obtain enough lung tissue for a diagnosis. Similarly, in the case of severe idiopathic interstitial pneumonia, most lung tissue is replaced by fibrous connective tissue, and no useful lung tissue can be obtained. This weak point may be improved by contrastenhanced ultrasound-guided biopsy so that the necrotic part can be shown and avoided. It is recommended that a second biopsy be performed if USLB gives a negative pathological result, but other examinations, such as CT or PET-CT, highly suspect the lesion to be malignant.

The USLB has high efficiency in the diagnosis of lung tumours. Only 20 cases of tumours were missed by USLB. Because some tumours can encompass a large range of necrosis and some are multicentric and mixed with infectious pulmonary consolidation, USLB may fail to obtain the proper tissue for pathological examinations. Multipoint puncture and contrast-enhanced ultrasoundguided biopsy may raise the positive rate for those cases. 

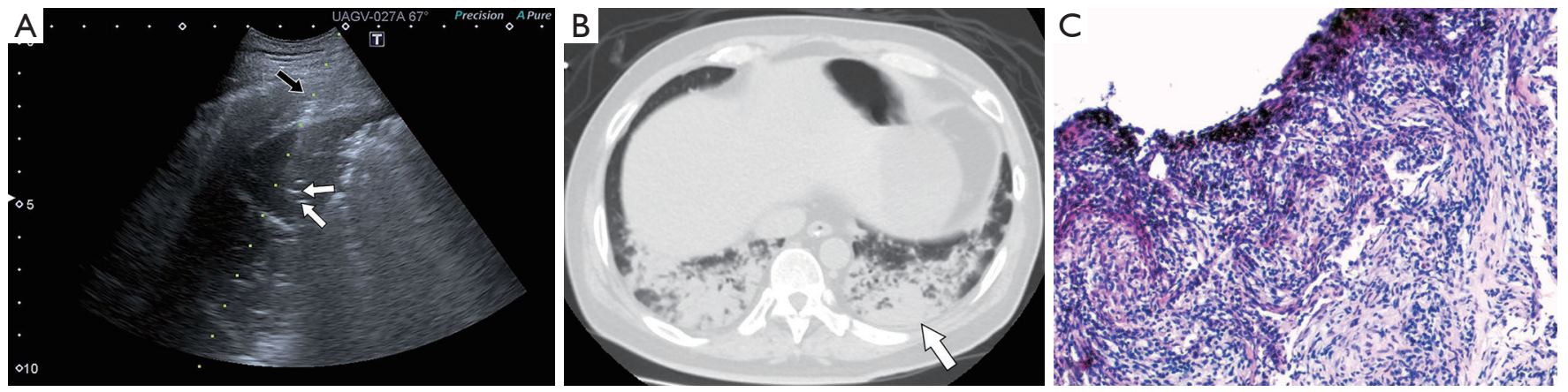

Figure 1 Images show the ultrasound-guided biopsy procedure of a 52-year-old male patient who came to the hospital because of aspiration pneumonia, and the USLB culture result was Klebsiella pneumonia. (A) The lung specimens were acquired with real-time ultrasoundguided biopsy. The path of the needle (black arrow) and the dense echo gas in the lesion (white arrow) is shown; (B) CT image shows lung consolidation (white arrow) in the target lesion; (C) histopathology of the specimen showed acute inflammation of the lung.

Table 4 Complications of USLB (some patients had two or more complications)

\begin{tabular}{|c|c|c|c|}
\hline Complications & USLB case count & Location of lesions & Concurrent lung diseases (number of cases) \\
\hline Blood in phlegm & $2.6 \%$ (13 cases) (lasted for $1-4$ days) & $\begin{array}{l}\text { Right lobe: } 12 \text { cases } \\
\text { Left lobe: } 1 \text { case }\end{array}$ & $\begin{array}{l}\text { Asthma [1], bronchiectasis [2], emphysema } \\
\text { [2], ILD [2] and COPD [1] }\end{array}$ \\
\hline Fever & $1.6 \%$ (8 cases) & $\begin{array}{l}\text { Right lobe: } 6 \text { cases } \\
\text { Left lobe: } 2 \text { cases }\end{array}$ & None \\
\hline Pneumothorax & $\begin{array}{l}1.2 \% \text { ( } 6 \text { cases, with } 1 \text { case of delayed } \\
\text { pneumothorax })\end{array}$ & $\begin{array}{l}\text { Right lobe: } 5 \text { cases } \\
\text { Left lobe: } 1 \text { case }\end{array}$ & Emphysema [1] and ILD [3] \\
\hline Haemoptysis & $\begin{array}{l}2.4 \% \text { ( } 12 \text { cases, one patient coughed over } \\
200 \mathrm{~mL} \text { and was treated with suction therapy) }\end{array}$ & $\begin{array}{l}\text { Right lobe: } 9 \text { cases } \\
\text { Left lobe: } 3 \text { cases }\end{array}$ & COPD [3] and ILD [1] \\
\hline
\end{tabular}

USLB, ultrasound-guided lung biopsy; ILD, interstitial lung disease; COPD, chronic obstructive pulmonary diseases.

The positive rate of USLB lung tissue cultures was $18.3 \%$, which is not very high. Sixty-three percent (27/43) of the cases of Mycobacterium infection were diagnosed by lung tissue acid-fast staining, Gene-Xpert and lung tissue cultures from the specimen obtained by USLB. Eighty percent (12/15) of the cases of fungal infections were diagnosed by USLB lung tissue cultures and Gomori methenamine staining. USLB diagnosed 4 out of the 5 cases of Aspergillus fumigatus infections, which is the most common fungus infection among all fungi infections diagnosed by USLB. Only $41 \%$ (18/44) of the cases of non- mycobacterial bacterial infections were diagnosed by USLB tissue cultures, which implies that USLB tissue culture is not sufficient for the diagnosis of bacterial infections. Burkbolderia cepacia is the most common bacteria diagnosed by USLB culture. A possible reason for the low accuracy for bacterial infections may be that most bacterial infections are diffuse in the lung, and USLB cannot reach the part where the bacteria are concentrated. However, sputum cultures and bronchoalveolar lavage fluid cultures, which collect specimens from all parts of the lung, have a much higher positive rate than lung tissue cultures. Therefore, 
if the lesion is localized, a USLB tissue culture is possibly necessary, especially when Mycobacterium infections or fungi infections are suspected because while the sputum culture and BALF may be contaminated during the procedure, lung tissue is less likely to be contaminated. In addition, USLB cultures may be better than TBLB cultures because the bronchoscope cannot obtain tissue from the deep part of the lung, and USLB is simpler than a bronchoscopy procedure. In a study, TBLB for pathological and bacterial investigations provided only limited value for Mycobacterium avium complex (MAC) diagnoses, with a positive rate of only $28.9 \%$ (16), which is far lower than that of sputum cultures. However, if the lesion is dispersed and diffused, lung tissue cultures, sputum cultures and bronchoalveolar lavage fluid cultures may be all needed to diagnose microbe infections and perform drug susceptibility tests. New methods of detecting pathogenic microbes, such as metagenomic next-generation sequencing (mNGS), may make better use of lung tissue for microbe detection (17).

Only one case of severe complications occurred during USLB. The patient experienced severe pulmonary haemorrhage, and $200 \mathrm{~mL}$ of blood was aspirated from the trachea. The patient was successfully rescued. No patients died because of USLB. The longest time of blood in the phlegm was 4 days. Eight patients had low fevers and were treated with antibiotics. Twelve patients had chest pain, which was relieved in 2 days. Six patients had pneumothorax, and one patient had delayed pneumothorax, which was found 8 hours after the procedure. The patient who had delayed pneumothorax was treated with thoracic close drainage and recovered in a week. Manual aspiration in the biopsy-side down position may reduce the rate of delayed pneumothorax according to a study (18). The other 5 patients with pneumothorax recovered in 1 week. Since the operator can avoid large bronchi during USLB with real-time vision, the incidence of pneumothorax was much lower than that of CT-guided lung biopsy [1.2\% to $27.3 \%$ (11)]. Two patients experienced pleural reactions, including nausea, shortness of breath and cold sweat, and both recovered in 1 day. Therefore, USLB is relatively safe, but first-aid support is still needed in cases of emergency.

Our research has certain limitations. The retrospective design creates a risk for selection bias. Because of the retrospective characteristics, the variables selected in our study were not comprehensive. For example, not all lung tissue culture results of all patients could be obtained. The chest CT, ultrasound and clinical course before biopsy affect the priority the specimen submission, creating a large bias.
A prospective study is needed to compare the efficiency of USLB with that of other methods.

\section{Conclusions}

USLB is a safe and effective method for diagnosing peripheral lung lesions with a high accuracy $(82.0 \%)$ and low complication rate $(9.0 \%)$. Lung tissue pathology and cultures have good diagnostic value for tuberculosis and fungi infections, especially in Cryptococcus neoformans and Aspergillus fumigatus infections. Lung tissue cultures can also diagnose many bacterial infections and can contribute to the selection of antibiotics.

\section{Acknowledgments}

Funding: None.

\section{Footnote}

Conflicts of Interest: The authors have no conflicts of interest to declare.

Ethical Statement: The authors are accountable for all aspects of the work in ensuring that questions related to the accuracy or integrity of any part of the work are appropriately investigated and resolved. "The patients consented to publish their examination results and radiological images anonymously." is the information approved by IEC of our hospital.

Open Access Statement: This is an Open Access article distributed in accordance with the Creative Commons Attribution-NonCommercial-NoDerivs 4.0 International License (CC BY-NC-ND 4.0), which permits the noncommercial replication and distribution of the article with the strict proviso that no changes or edits are made and the original work is properly cited (including links to both the formal publication through the relevant DOI and the license). See: https://creativecommons.org/licenses/by-nc-nd/4.0/.

\section{References}

1. Zhan P, Zhu QQ, Miu YY, et al. Comparison between endobronchial ultrasound-guided transbronchial biopsy and CT-guided transthoracic lung biopsy for the diagnosis of peripheral lung cancer: a systematic review and metaanalysis. Transl Lung Cancer Res 2017;6:23-34. 
2. Wang C, Zeng D, Lei W, et al. Diagnostic value of computed tomography-guided percutaneous needle biopsy versus radial probe endobronchial ultrasoundguided transbronchial lung biopsy in peripheral pulmonary lesions. Zhonghua Jie He He Hu Xi Za Zhi 2015;38:897-900.

3. Chang HC, Yang MC. Systemic air embolism after percutaneous computed tomography-guided lung biopsy due to a kink in the coaxial biopsy system: a case report. BMC Med Imaging 2018;18:1.

4. Lang D, Reinelt V, Horner A, et al. Complications of CT-guided transthoracic lung biopsy : A short report on current literature and a case of systemic air embolism. Wien Klin Wochenschr 2018;130:288-92.

5. Sakatani T, Amano Y, Sato J, et al. Air embolism after CT-guided percutaneous lung biopsy. Jpn J Clin Oncol 2018;48:699-700.

6. Ialongo P, Ciarpaglini L, Tinti MD, et al. Systemic air embolism as a complication of percutaneous computed tomography guided transthoracic lung biopsy. Ann R Coll Surg Engl 2017;99:e174-6.

7. April D, Sandow T, Scheibal J, et al. Clinical Images: Left Atrial Air Embolism Following Computed TomographyGuided Lung Biopsy. Ochsner J 2017;17:141-3.

8. Matsuura H, Takaishi A, Oonishi N, et al. Air embolism and CT-guided lung biopsy. QJM 2017;110:465-6.

9. Fiore L, Frenk NE, Martins GLP, et al. Systemic Air Embolism after Percutaneous Lung Biopsy: A Manageable Complication. J Radiol Case Rep 2017;11:6-14.

10. Yun S, Kang H, Park S, et al. Diagnostic accuracy and complications of CT-guided core needle lung biopsy of solid and part-solid lesions. Br J Radiol 2018;91:20170946.
11. Lim WH, Park CM, Yoon SH, et al. Time-dependent analysis of incidence, risk factors and clinical significance of pneumothorax after percutaneous lung biopsy. Eur Radiol 2018;28:1328-37.

12. Taleb S, Jalaeian H, Frank N, et al. Is a Routine Chest X-ray Necessary in Every Patient After Percutaneous CTGuided Lung Biopsy? A Retrospective Review of 278 Cases. Cardiovasc Intervent Radiol 2017;40:1415-20.

13. Narula N, Siddiqui F, Siddiqui AH, et al. Delayed Pneumothorax: A Potential Complication Of Transbronchial Lung Biopsy. Respir Med Case Rep 2018;23:170-2.

14. Lee MH, Lubner MG, Hinshaw JL, et al. Ultrasound Guidance Versus CT Guidance for Peripheral Lung Biopsy: Performance According to Lesion Size and Pleural Contact. AJR Am J Roentgenol 2018;210:W110-7.

15. Laursen CB, Naur TM, Bodtger U, et al. Ultrasoundguided Lung Biopsy in the Hands of Respiratory Physicians: Diagnostic Yield and Complications in 215 Consecutive Patients in 3 Centers. J Bronchology Interv Pulmonol 2016;23:220-8.

16. Sekine A, Saito T, Satoh H, et al. Limited value of transbronchial lung biopsy for diagnosing Mycobacterium avium complex lung disease. Clin Respir J 2017;11:1018-23.

17. Li H, Gao H, Meng H, et al. Detection of Pulmonary Infectious Pathogens From Lung Biopsy Tissues by Metagenomic Next-Generation Sequencing. Front Cell Infect Microbiol 2018;8:205.

18. Zeng LC, Yang HF, Xu XX, et al. Manual aspiration in the biopsy-side down position to deal with delayed pneumothorax after lung biopsy. J Thorac Dis 2018;10:241-6.
Cite this article as: Zhao ZL, Peng LL, Wei Y, Li Y, Wang GM, Yu MA. The accuracy of ultrasound-guided lung biopsy pathology and microbial cultures for peripheral lung lesions. J Thorac Dis 2020;12(3):858-865. doi: 10.21037/jtd.2019.12.92 